\title{
E-101 Solution
}

National Cancer Institute

\section{Source}

National Cancer Institute. E-101 Solution. NCI Thesaurus. Code C114986.

An oxidant-generating coupled-enzyme system-based, topical solution comprised of two enzymes, Aspergillus niger-derived glucose oxidase (GO) and porcine myeloperoxidase (p-MPO), as well as glucose, sodium chloride and stabilizing amino acids, with potential broad-spectrum microbicidal activity. Following direct administration of E-101 solution into the surgical incisional wound via microspray, the enzyme GO converts oxygen into hydrogen peroxide ( $\mathrm{H} 2 \mathrm{O} 2$ ). In turn, p-MPO catalyzes the reaction of $\mathrm{H} 2 \mathrm{O} 2$ with hypochlorous acid $(\mathrm{HOCl})$, which is formed through oxidation of the chloride ion, to generate sing let oxygen $\left(\mathrm{O}_{2} *\right.$ ). As p-MPO binds to microorganisms, $\mathrm{O} 2$ * is able to exert direct oxidative damage to microorganisms, resulting in potent antimicrobial activity. E101 may act as an anti-bactericidal agent against a variety of microorganisms, including multidrug-resistant strains. This may prevent infection at the surgical site. 